\title{
INFLUENCE OF NANOPARTICLES DIAMETER ON STRUCTURAL PROPERTIES OF MAGNETIC FLUID IN MAGNETIC FIELD
}

\author{
Jozef Kúdelčík ${ }^{*}$ - Peter Bury ${ }^{*}$ - Štefan Hardoň ${ }^{*}$ \\ Peter Kopčanský $^{* *}$ - Milan Timko ${ }^{* *}$
}

\begin{abstract}
The properties of magnetic fluids depend on the nanoparticle diameter, their concentration and the carrier liquid. The structural changes in magnetic fluids with different nanoparticle diameter based on transformer oils TECHNOL and MOGUL under the effect of a magnetic field and temperature were studied by acoustic spectroscopy. At a linear and jump changes of the magnetic field at various temperatures a continuous change was observed of acoustic attenuation caused by aggregation of the magnetic nanoparticles to structures. From the anisotropy of acoustic attenuation and using the Taketomi theory the basic parameters of the structures are calculated and the impact of nanoparticle diameters on the size of structures is confirmed.
\end{abstract}

K e y w or d s: magnetic nanoparticles, transformer oil, acoustic attenuation

\section{INTRODUCTION}

Magnetic fluids have found wide application in technology, medicine and other areas to improve the properties of various materials $[1,2]$. The properties of transformer oil utilized in power technology can be improved by adding the magnetic nanoparticles. The transformer oil-based magnetic fluids have better thermal and insulating properties. The aggregation effects of magnetic nanoparticles in an external magnetic field strongly influences the electric breakdown [3-6].

Propagation of an acoustic wave in magnetic fluids was studied in several works both theoretically and experimentally [7-12]. These works have also showed that the magnetic field has an important effect on the change of acoustic attenuation. This is caused by aggregation of the nanoparticles in the magnetic fluid along the magnetic field direction into oligomers, chains or clusters $[9,12-$ 15]. These shapes depend on both particle-particle interactions represented by the coupling constant and particlefield interactions, which are also important in computer simulations $[16,17]$. Information about the structures can be obtained from the study of the anisotropy of the acoustic attenuation coefficient $[9,11,13]$. However, the structures can be complicated and two kinds of motions must be taken account. The first one is the rotational motion and the second the translation motion, which were analysed by the Taketomi model $[13,18,19]$.

In this paper the effect is studied of the magnetic field, time and temperature on the structure of magnetic fluids based on transformer oils TECHNOL and MOGUL with same concentration but various diameters of nanoparticles. The structure changes are studied by acoustic spectroscopy and the observed results for both kinds of magnetic fluids are discussed and compared.

\section{EXPERIMENTAL RESULTS}

Transformer oils TECHNOL and MOGUL were used as carrier liquids in the studied magnetic fluids. The magnetic fluids used in experiments consisted of magnetite nanoparticles $\left(\mathrm{FeO} \times \mathrm{Fe}_{2} \mathrm{O}_{3}\right)$ with mean diameters $d=11.1 \mathrm{~nm}$ and $d=7.9 \mathrm{~nm}(\sigma=0.28 \mathrm{~nm})$ coated with oleic acid as a surfactant and dispersed in respective transformer oils. The basic properties of investigated magnetic fluids, such as the density, saturation magnetization and volume fraction were equal to $0.882 \mathrm{~g} / \mathrm{cm}^{3}$ and $4.73 \mathrm{mT}$ for $1 \%$ magnetic fluid (MF) based on TECHNOL and $0.89 \mathrm{~g} / \mathrm{cm}^{3}, 3.39 \mathrm{mT}$ for $1 \%$ magnetic fluid based on MOGUL. The experimental arrangement as in $[15,20]$ was used for measuring the attenuation of the acoustic wave at frequency $12.6 \mathrm{MHz}$.

Figure 1 shows the changes of acoustic attenuation for a linear change of the magnetic field ( $3.3 \mathrm{mT}$ per minute) to the maximal value $200 \mathrm{mT}$ for $\mathrm{MF}$ TECHNOL and to $300 \mathrm{mT}$ for MF MOGUL. One can see that the observed curves of acoustic attenuation for both MFs have different shapes. The results indicate a significant effect of the magnetic field and temperature on the acoustic attenuation. The measurements for temperature $25^{\circ} \mathrm{C}$ and lower - MF TECHNOL, Fig. 1(a)- show large changes of

\footnotetext{
* Department of Physics, University of Žilina, Univerzitná 1, 01026 Žilina, ${ }^{* *}$ Department of Magnetism, IEP SAS, Watsonova 47, 04001 Košice, kudelcik@fyzika.uniza.sk
} 

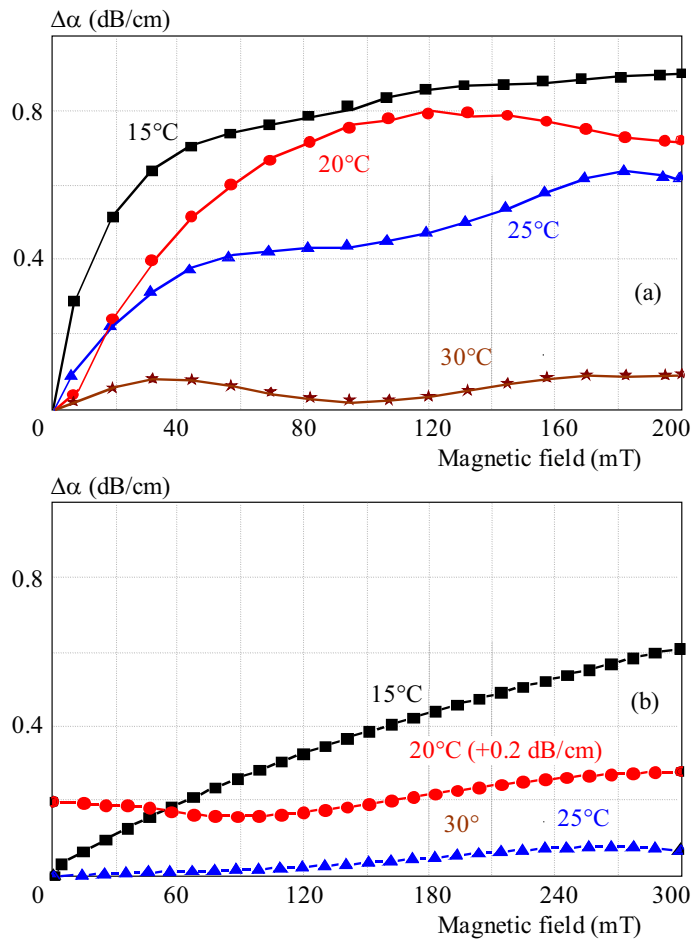

Fig. 1. The dependence of the changes of acoustic attenuation on the magnetic field for (a) - MF TECHNOL and (b) MF MOGUL measured at various temperatures. Measurement at temperature $20^{\circ} \mathrm{C}$ in case (b) is shifted by $+0.2 \mathrm{~dB} / \mathrm{cm}$ for better resolution

Table 1. Parameters describing magnetic fluids based on the TECHNOL and MOGUL obtained from the fit of measured anisotropy data

\begin{tabular}{c|ccc|ccc}
\hline & \multicolumn{3}{|c|}{ MF TECHNOL } & \multicolumn{3}{|c}{ MF MOGUL } \\
\hline Temperature & $20{ }^{\circ} \mathrm{C}$ & $25{ }^{\circ} \mathrm{C}$ & $30{ }^{\circ} \mathrm{C}$ & $15^{\circ} \mathrm{C}$ & $20{ }^{\circ} \mathrm{C}$ & $25^{\circ} \mathrm{C}$ \\
$4 / 3 \eta_{S}+\eta_{V}$ & 0.29 & 0.24 & 0.23 & 0.35 & 0.32 & 0.24 \\
$k\left(\mathrm{~N} \mathrm{~m}^{-1}\right)$ & 2.3 & 0.55 & 0.24 & 1.5 & 1.1 & 0.5 \\
$a(n m)$ & 50 & 34 & 24 & 71 & 20 & 16 \\
$10^{-17} N\left(\mathrm{~m}^{-3}\right)$ & 255 & 277 & 560 & 22.7 & 507 & 549 \\
$V \times N(\%)$ & 0.33 & 0.11 & 0.08 & 0.34 & 0.17 & 0.09 \\
\hline
\end{tabular}

the acoustic attenuation with increasing magnetic field. These changes originated from the process of particle agglomeration to oligomers, thin chains or created clusters. With a decrease of temperature the creation of clusters is more effective because the Brown thermal motion is not so effective to destroy them [7]. At $30^{\circ} \mathrm{C}$ the influence of the magnetic field on the acoustic attenuation is weak. We can suppose that only oligomers exist and mostparticles are practically free. For MF MOGUL the changes of the acoustic attenuation are smaller although the maximal magnetic field was higher. At the lowest temperature $15^{\circ} \mathrm{C}$, there is a significant increase of attenuation with increasing magnetic field. At higher temperatures, $20^{\circ} \mathrm{C}$ and $25^{\circ} \mathrm{C}$, the changes of acoustic attenuation depend on the magnetic field only weakly. At these temperatures the nanoparticles are practically free or create small oligomers.
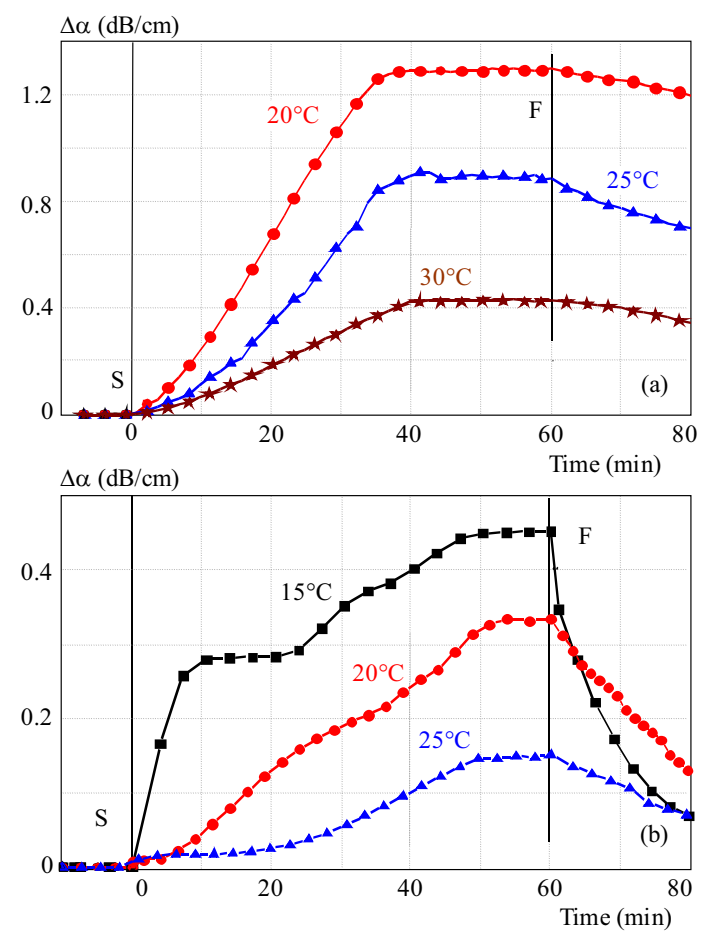

Fig. 2. Experimental data of the changes of acoustic attenuation for a jump change of the magnetic field to value (a) $200 \mathrm{mT}$ for MF TECHNOL and (b) - $300 \mathrm{mT}$ for MF MOGUL measured at various temperatures

Figure 2 present the changes of acoustic attenuation for a jump change of the magnetic field from zero to value $200 \mathrm{mT}$ (MF TECHNOL) or $300 \mathrm{mT}$ (MF MOGUL) and kept constant during the next 60 minutes. The change of the acoustic attenuation at the jump change of the magnetic field depended on temperature. For $1 \% \mathrm{MF}$ TECHNOL, Fig. 2(a), the progress of the change of the acoustic attenuation was very slow at a constant magnetic field. It can be seen that only after 40 minutes the attenuation reached constant values. The processes of aggregation had a long time scale. After the magnetic field was switched off, the change of the acoustic attenuation did not return to the initial value and its value decreased very slowly. From the long time of decrease it follows that the lifetimes of the created structures were several tens of minutes. In the case of the MF MOGUL the acoustic attenuation increased in a similar way for all temperatures during the first 50 minutes until it reached constant values, the magnitude also depended on temperature. After the magnetic field is switched-off, the acoustic attenuation decreased to its initial value more quickly than for MF with bigger nanoparticles.

Parameters characterizing the arrangement of nanoparticles $(k$ - constant of recovering force, $a$ - radius of clusters, $N$ - density of clusters and volume concentration of all clusters $V \times N)$ can be obtained from the analysis of the dependence of the acoustic attenuation on the angle $\varphi$ between the acoustic wave vector $\boldsymbol{k}$ and the direction of magnetic field $\boldsymbol{B}$ (anisotropy). These parameters can be calculated using the Taketomi theory [18] 
that takes into account both translational and rotational movement of nanoparticle formations.

The anisotropy of acoustic attenuation measured at magnetic field $200 \mathrm{mT}$ for four different temperatures of MFs is shown in Fig. 3. The measurements were made in the following steps: at the beginning, a jump change of the magnetic field from $0 \mathrm{mT}$ to $200 \mathrm{mT}$ and during the next 120 minutes waiting for a steady-state. Then at $200 \mathrm{mT}$, the angle between the direction of the magnetic field and the wave vector of the acoustic wave was changed by 10 degrees to 90 degrees. Measurement of the acoustic attenuation was done at a new angle after 15 minutes of stabilization. The solid lines represent fitting of the experimental data using theoretical functions $[13,14,18]$, where the main parameters are presented in Table 1 . It can be seen that the changes of acoustics attenuation for MF TECHNOL are higher than for MF MOGUL. The measured anisotropy has a maximum value, its position depends on temperature, however, only for lower temperatures, for MF MOGUL: $15{ }^{\circ} \mathrm{C}-40^{\circ} \mathrm{C}$; for MF TECHNOL: $20^{\circ} \mathrm{C}-$ $45^{\circ} \mathrm{C}, 25^{\circ} \mathrm{C}-50{ }^{\circ} \mathrm{C}$.

\section{DISCUSSION}

Magnetic nanoparticles are mono-domain and in a magnetic field their moments are mainly oriented in the direction of the applied field. Hence, in a carrier liquid there is a high probability to create dimers, trimers, higher oligomers or new structures $[7,10,13,14]$. These structures enlarge (thin chains and clusters) with the magnetic field and have an influence on the acoustic attenuation $[5,12]$. This effect is clearly visible from the measurements presented in Figures 1 and 2. At a slow increase of the magnetic field (Fig. 1) there is enough time for gradual creation of these structures. A similar effect was observed onapplication of a constant magnetic field (Fig. 2), where the processes leading to the creation of structures are also time dependent. From these experimental measurements one can conclude that for both MFs long thin chains or clusters can be created at lower temperatures. However, the type of structures depends on the size of nanoparticles, coupling constant, time for the creation (several tens of minutes [13]) and viscosity of the given magnetic fluid. The energy consumed by the oscillations of the particles increases with their size which was also reflected in the higher acoustic attenuation observed in MF TECHNOL.

The parameters characterizing the structures of nanoparticles were calculated from the anisotropy of acoustic attenuation measured at various temperatures. On the basis of the calculated radius (Table 1 ) at the lowest temperature $\left(15^{\circ} \mathrm{C}\right.$ for MF MOGUL, $20^{\circ} \mathrm{C}$ for $\mathrm{MF}$ TECHNOL) one can conclude that in the bulk in chains there are more than 6 nanoparticles. Nanoparticles created clusters and bigger structures can exist. These clusters create rough chains. The difference ine the development of anisotropy at various temperatures is caused by the size of nanoparticles in the studied MFs. For smaller nanoparticles (MF MOGUL) the thermal Brown motion (speed) and viscosity are higher so at temperatures higher than $20^{\circ} \mathrm{C}$ only dimers (trimers) can exist. For bigger nanoparticles (MF TECHNOL) the structures are bigger and they have better stability. Smaller viscosity and stable structures result in a more pronounced anisotropy for this type of MF (Fig. 3a). At higher temperature there are only 2-3 nanoparticles in the bulk, so they can create only thin chains. Both the smaller number of nanoparticles in clusters or chains and their smaller size have a smaller influence on the acoustic attenuation.
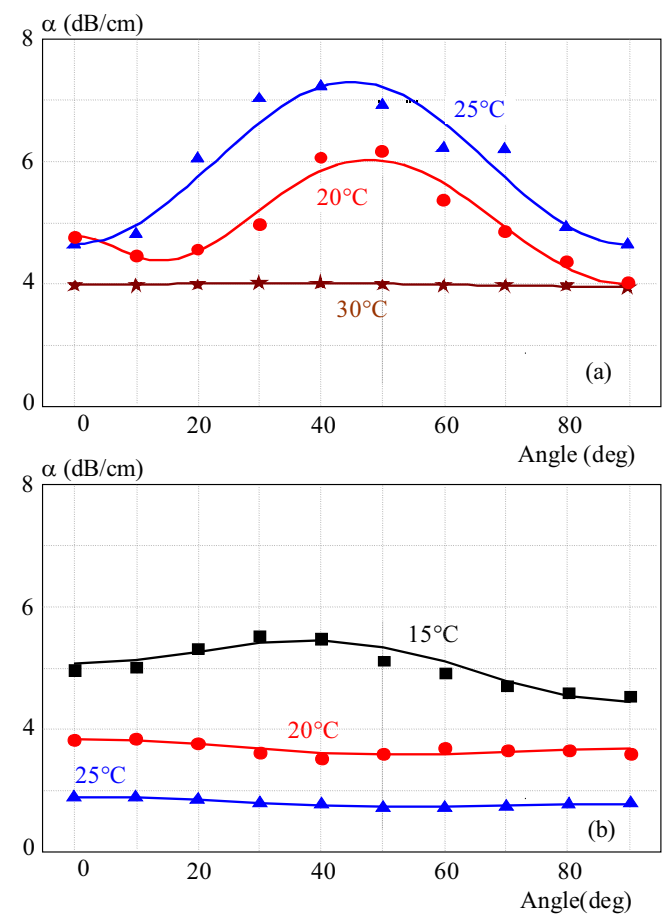

Fig. 3. Anisotropy measurement of the acoustic attenuation ( $B=$ $200 \mathrm{mT}$ ) for (a) - MF TECHNOL and (b) - MF MOGUL

The measurements were performed at various temperatures and for all cases one cansee strong influence of temperature on the change of acoustic attenuation. At lower temperatures, creation of nanoparticle structures is more effective because the Brown thermal motion is not so effective to destroy these structures. The thermal motion increases with increasing temperature and it results in a decrease in the number and size of structures. The reduced size of clusters and the shorter length of chains then lead to a decrease of acoustic attenuation. The changes of acoustic attenuation in the case of MF MOGUL were the largest at a temperature of $15^{\circ} \mathrm{C}$. At higher temperatures the changes of acoustic attenuation were also independent of the magnetic field. For MF TECHOL the situation is different because until $30^{\circ} \mathrm{C}$ there is no change of the acoustic coefficient. At higher temperatures the change of acoustics attenuation is much smaller for both types of MF because the effect of thermal motion is more significant. At these temperatures the numbers of smaller structures (dimers, trimers) are higher but their concentration is smaller (Tab. $1, V \times N(\%)$ ), so finally they have a smaller effect on the acoustic attenuation. 


\section{CONCLUSION}

The changes of acoustic attenuation in magnetic fluids in the magnetic field were measured. Two kinds of magnetic fluids based on transformer oils MOGUL and TECHNOL were studies to describe the aggregation structures of nanoparticles. The magnetic field, temperature and nanoparticles diameter are important factors that influence the structures of the investigated magnetic fluids. The effect of different nanoparticle diameters in the studies magnetic fluids on the values of acoustic attenuation at various temperatures in the magnetic field was observed. Using Taketomi theory and the anisotropy of the acoustic attenuation the radius of clusters, their density and viscous term were determined in dependence on temperature.

\section{Acknowledgement}

This work was financially supported by grants VEGA $1 / 0624 / 13$ and $2 / 0045 / 13$. The authors wish to thank also for the support to the R\&D operational program Centrum of Excellence of Power Electronics Systems and Materials for their Components, No. OPVaV-2008/2.1/01-SORO, ITMS 2622012046 funded by the European Community.

\section{REFERENCES}

[1] ODENBACH, S.: Ferrofluids-Magnetically Controlled Suspensions, Colloids and Surfaces A: Physicochemical and Engineering Aspects 217 (2003), 171-178.

[2] SARRESHTEDARI, F.-KOBAKI, H.-GAMBY, J.-NGO, KA.-KRAUSE, HJ.-FARDMANESH, M.: Aggregation and Detection of Magnetic Nanoparticles in Microfluidic Channels, Journal of Electrical Engineering 63 No. 7s (2012), 27-30.

[3] LV, YZ.-ZHOU, Y.-LI, CR.-WANG, Q. : Recent Progress in Nanofluids Based on Transformer Oil: Preparation and Electrical Insulation Properties, IEEE Electrical Insulation Magazine 30 No. 5 (2014), 23-32.

[4] GHASEMI, J.-JAFARMADAR, S.-NAZARI, M. : Effect of Magnetic Nanoparticles on the Lightning Impulse Breakdown Voltage of Transformer Oil, Journal of Magnetism and Magnetic Materials 389 (2015), 148-152.

[5] JEON, HP.-LEE, J. C. : Numerical Simulation of Particle Concentration in Dielectrophoretic Flow for High Voltage Applications, Materials Research Bulletin 58 (2014), 181-185.

[6] CIMBAlA, R.-KINARY, J.-GERMAN-SOBEK, M.-BUCKO, S.-KURIMSKÝ, J.-DZMURA, J.: Polarization Phenomena in Magnetic Liquids, Chemické listy 109 No. 2 (2015), $117-124$.

[7] JOZEFCZAK, A.-HORNOWSKI, T.-SKUMIEL, A.: Temperature Dependence of Particle Size Distribution in Transformer Oil-Based Ferrofluid, International Journal of Thermophysics 32 (2011), 795-806.

[8] HORNOWSKI, T.-JOZEFCZAK, A.-KOLODZIEJCZYK, B. -TIMKO, M.-SKUMIEL, A.-RAJŇÁK, M. : The Effect of Particle Aggregate Shape on Ultrasonic Anisotropy in Concentrated Magnetic Fluids, Journal of Physics D: Applied Physics 48 No. 17 (2015), 175303.

[9] SKUMIEL, A.: The Effect of Temperature on the Anisotropy of Ultrasound Attenuation in a Ferrofluid, Journal of Physics D: Applied Physics 37 No. 22 (2004), 3073.

[10] SOKOLOV, V.: Wave Propagation in Magnetic Nanofluids (A review), Acoustical Physics 56 No. 9 (2010), 972-988.
[11] PATEL, JK.-PAREKH, K.: Effect of Carrier and Particle Concentration on Ultrasound Properties of Magnetic Nanofluids, Ultrasonics 55 (2015), 26-32.

[12] PAREKH, K.-PATEL, J.-UPADHYAY, RV.: Ultrasonic Propagation: A Technique to Reveal Field Induced Structures in Magnetic Nanofluids, Ultrasonics 60 (2015), 126-132.

13] KÚDELČÍK, J.-BURY, P.-KOPČANSKÝ, P.-TIMKO, M. : Structure of Nanoparticles in Transformer Oil-Based Magnetic Fluids; Anisotropy of Acoustic Attenuation, Journal of Magnetism and Magnetic Materials 388 (2015), 28-34.

14] KÚDELČÍK, J.-BURY, P.-KOPČANSKÝ, P.-TIMKO, M. : Temperature Effect on Anisotropy of Acoustic Attenuation in Magnetic Fluids based on Transformer Oil, Comunication 16 No. 1 (2014), 33-40.

[15] KÚDELČÍK, J.-BURY, P.—DRGA, J.-KOPČANSKÝ, P.ZÁVIŠOVÁ, V.-TIMKO, M. : The Structure of Transformer Oil-Based Magnetic Fluids Using Acoustic Spectroscopy, Journal of Magnetism and Magnetic Materials 326 (2013), 75-80.

[16] AOShimA, M.-SATOH, A.: Two Dimensional Monte-Carlo Simulations of a Colloidal Dispersion Composed of Polydisperse Ferromagnetic Particles in Magnetic Field, Journal of Colloid and Interface Science 288 (2005), 475-488.

[17] KOLTUNOWICZ, TN.-FEDOTOVA, JA.-ZHUKOWSKI, P.-SAAD, A.-FEDOTOV, A.-KASIUK, JV.-LARKIN, AV.: Negative Capacitance in (FeCoZr)-(PZT) Nanocomposite Films, Journal of Physics D: Applied Physics 46 No. 12 (2013), 125304.

[18] TAKETOMI, S.: The Anisotropy of the Sound Attenuation in Magnetic Fluid under an External Magnetic Field, Journal of the Physical Society of Japan 55 (1986), 838-844.

[19] SHLIOMIS, M.-MOND, M.-MOROZOV, KI. : Ultrasound Attenuation in Ferrofluids, Physics Review Letter 101 (2008), 074505 .

[20] KÚDELČÍK, J.-BURY, P.—KOPČANSKÝ, P.-TIMKO, M.-ZÁVIŠOVÁ, V.: Acoustic Properties of Magnetic Fluids based on Transformer Oil under Magnetic Field, Journal of Electrical Engineering 64 No. 6 (2013), 381-385.

Received 14 July 2015

Jozef Kúdelčík was born in 1975. Since 1998 he has been working as a researcher at the Department of Physics at the University of Žilina, at present interested in in the processes in magnetic fluids in a magnetic field studied by acoustic spectroscopy.

Peter Bury graduated in 1972. Currently is Professor of Physics of Condensed Matter and Acoustics at Department of Physics, Faculty of Electrical Engineering, Žilina University. The most of his research work was orientated on the study of semiconductors and semiconductor structures using acoustic methods.

Štefan Hardoň born in 1988 graduated from the Department of Telecommunication at the University of Žilina, and currently he is a PhD student involved in acoustic techniques for research of semiconductor structures.

Peter Kopčanský born, in 1955, graduated from the Department of Theoretical Physics of the Faculty of Sciences at Šafarik University in Košice. PhD in 1985, associate prof in 2002. Since 1995 he has been working as a researcher at the Department of Magnetism, Institute of Experimental Physics SAS.

Milan Timko born in 1954, graduated from the Department of Experimental Physics of the Faculty of Sciences at UPJ in Košice, PhD in 1984. Since 1984 he has been working as a scientific worker at the Department of Magnetism at the Institute of Experimental Physics SAS. 